\title{
Desulfopila inferna sp. nov., a sulfate-reducing bacterium isolated from the subsurface of a tidal sand-flat
}

\author{
Correspondence \\ Antje Gittel \\ antje.gittel@biology.au.dk
}

\author{
Antje Gittel, ${ }^{1} \dagger$ Michael Seidel, ${ }^{1}$ Jan Kuever, ${ }^{2}$ Alexander S. Galushko, ${ }^{3}$ \\ Heribert Cypionka ${ }^{1}$ and Martin Könneke ${ }^{1}$
${ }^{1}$ Institut für Chemie und Biologie des Meeres, Universität Oldenburg, Carl von Ossietzky-Strasse 9-11, Postfach 2503, D-26111 Oldenburg, Germany \\ ${ }^{2}$ Bremen Institute for Materials Testing, Paul-Feller-Strasse 1, D-28199 Bremen, Germany \\ ${ }^{3}$ Max Planck Institute for Marine Microbiology, Celsiusstrasse 1, D-28359 Bremen, Germany
}

\begin{abstract}
A Gram-negative, rod-shaped, sulfate-reducing bacterium (strain JS_SRB250Lac ${ }^{\top}$ ) was isolated from a tidal sand-flat in the German Wadden Sea. 16S rRNA gene sequence analysis showed that strain JS_SRB250Lac ${ }^{\top}$ belonged to the Desulfobulbaceae (Deltaproteobacteria), with Desulfopila aestuarii $\mathrm{MSL86}^{\top}$ being the closest recognized relative (94.2\% similarity). Higher similarity (96.6\%) was shared with 'Desulfobacterium corrodens' IS4, but this name has not been validly published. The affiliation of strain JS_SRB250Lac ${ }^{\top}$ to the genus Desulfopila was further supported by analysis of aprBA gene sequences and shared physiological characteristics, in particular the broad range of organic electron donors used for sulfate reduction. Compared with Desulfopila aestuarii MSL86 ${ }^{\top}$, strain JS_SRB250 Lac ${ }^{\top}$ additionally utilized butyrate and succinate and grew chemolithoautotrophically with hydrogen as an electron donor. $\mathrm{CO}$ dehydrogenase activity was demonstrated, indicating that the reductive acetyl-CoA pathway (Wood-Ljungdahl pathway) was used for $\mathrm{CO}_{2}$ fixation. Results of cellular fatty acid analysis allowed chemotaxonomic differentiation of strain JS_SRB250Lac ${ }^{\top}$ from Desulfopila aestuarii MSL86 ${ }^{\top}$ by the presence of $\mathrm{C}_{17: 0}$ cyclo and the absence of hydroxy and unsaturated branched-chain fatty acids. Based on phylogenetic, physiological and chemotaxonomic characteristics, strain JS_SRB250Lac ${ }^{\top}$ represents a novel species of the genus Desulfopila, for which the name Desulfopila inferna sp. nov. is proposed. The type strain is JS_SRB250Lac ${ }^{\top}\left(=\right.$ DSM $_{1073}{ }^{\top}$ $=$ NBRC $103921^{\top}$ ).
\end{abstract}

Sandy surface sediments of tidal flats in the Wadden Sea are densely populated by micro-organisms and characterized by high remineralization rates (Ishii et al., 2004; de Beer et al., 2005; Billerbeck et al., 2006b; Musat et al., 2006). Due to their high permeability, seawater drains into the sediment and organic matter is filtered and enriched in

†Present address: Department of Biological Sciences, Microbiology, Aarhus University, Ny Munkegade 114, DK-8000 Aarhus C, Denmark.

Abbreviation: SRB, sulfate-reducing bacteria.

The GenBank/EMBL/DDBJ accession numbers for the nucleotide sequences reported in this study are AM774321, FJ548990 and FJ548989 (16S rRNA, dsrAB and aprBA gene sequences, respectively, of strain JS_SRB250Lac ${ }^{\top}$ ) and FJ548988 (aprBA gene sequence of Desulfopila aestuarii MSL86 ${ }^{\top}$ ).

A phase-contrast micrograph of cells of strain JS_SRB250Lac ${ }^{\top}$ and maximum-likelihood trees based on DsrAB and AprBA amino acid sequences are available as supplementary material with the online version of this paper. the sediment surface, fuelling microbial activity (Huettel \& Rusch, 2000; D’Andrea et al., 2002). In addition, porewater can be transported down several metres to deep sediments by a tide-driven hydraulic pressure gradient and provide microbial communities at these depths with utilizable substrates (Billerbeck et al., 2006a; Røy et al., 2008). This phenomenon was recently supported by the demonstration of large total prokaryotic cell numbers and the presence of a highly abundant and potentially active community of sulfate-reducing bacteria (SRB) at a depth of several metres of a tidal sand-flat ('Janssand', German Wadden Sea; Gittel et al., 2008). In the course of this investigation, strain JS_SRB250 $\mathrm{Lac}^{\mathrm{T}}$ and four closely related strains were isolated from highly diluted sediment samples from different depths and identified as forming a distinct cluster within the Desulfobulbaceae (Gittel et al., 2008). It was furthermore confirmed by in situ quantification (CARD-FISH; catalysed reporter depositionfluorescence in situ hybridization) that members of the 
Desulfobulbaceae and the Desulfobacteraceae dominated the sulfate-reducing community. Therefore, the newly isolated strains appeared to be representative of an in situ abundant and active fraction of SRB. The five isolated strains exhibited less than $95 \% 16 \mathrm{~S}$ rRNA gene sequence identity to the closest relative with a validly published name, Desulfopila aestuarii MSL86 ${ }^{\mathrm{T}}$ (Suzuki et al., 2007), but more than $96 \% 16 \mathrm{~S}$ rRNA gene sequence identity was shared with the marine sulfate reducer 'Desulfobacterium corrodens' IS4 (Dinh et al., 2004). The latter strain has not yet been described taxonomically. Strain JS_SRB250 acc $^{\mathrm{T}}$ was subjected to a phylogenetic, physiological and chemotaxonomic characterization and comparison with 'Desulfobacterium corrodens' IS4 and Desulfopila aestuarii MSL86 $^{\mathrm{T}}$.

Strain JS_SRB250Lac ${ }^{\mathrm{T}}$ was isolated from sediment at a depth of $2.5 \mathrm{~m}$ from a tidal sand-flat in the German Wadden Sea ('Janssand'; 53 44.177' N 007 41.970' E). Details of the sampling site have been described elsewhere (Beck et al., 2007; Røy et al., 2008). Enrichment and isolation of strain JS_SRB250Lac ${ }^{\mathrm{T}}$ were described previously (Gittel et al., 2008). Desulfopila aestuarii MSL86 ${ }^{\mathrm{T}}$ was kindly provided by Katsuji Ueki (Yamagata University, Japan). A culture of 'Desulfobacterium corrodens' IS4 was provided by Dennis Enning (Max Planck Institute for Marine Microbiology, Bremen, Germany).

Cultivation, growth experiments and strain maintenance were performed in an anoxic, carbonate-buffered, mineral medium as described previously (Gittel et al., 2008). Unless otherwise noted, incubations were carried out with an inoculum volume of $5 \%(\mathrm{v} / \mathrm{v})$ and at $20{ }^{\circ} \mathrm{C}$ in the dark. Gram-staining of heat-fixed cells was carried out as described by Murray et al. (1994). Cells of strain JS_SRB250 $\mathrm{Lac}^{\mathrm{T}}$ were Gram-negative, non-motile, straight rods with rounded ends, $0.3-0.5 \mu \mathrm{m}$ wide and 1.0-2.0 $\mu \mathrm{m}$ long (Supplementary Fig. S1, available in IJSEM Online). Longer cells, up to $5 \mu \mathrm{m}$, developed at low temperatures $\left(<15{ }^{\circ} \mathrm{C}\right)$. Cells of strain JS_SRB250Lac ${ }^{\mathrm{T}}$ formed lightbrown colonies in agar tubes and aggregated during growth in liquid medium. Formation of endospores was not observed.

Growth experiments were performed in triplicate and monitored by phase-contrast microscopy combined with photometric sulfide measurement (Cord-Ruwisch, 1985) and/or by the determination of cellular protein content (Bradford, 1976). Growth rates were calculated from linear regression of cellular protein as a function of time. The effect of $\mathrm{NaCl}$ concentration on growth was determined in mineral medium with $\mathrm{NaCl}$ concentrations between 1 and $50 \mathrm{~g} \mathrm{l}^{-1}$. Highest growth rates were observed at $\mathrm{NaCl}$ concentrations between 20 and $30 \mathrm{~g} \mathrm{l}^{-1}$. Growth did not occur at $\mathrm{NaCl}$ concentrations below $5 \mathrm{~g} \mathrm{l}^{-1}$. The temperature range for growth was determined in seawater medium $\left(28 \mathrm{~g} \mathrm{NaCl} \mathrm{l}^{-1}\right)$ and incubation at $4-50{ }^{\circ} \mathrm{C}$. Growth was observed between 10 and $35{ }^{\circ} \mathrm{C}$, with highest growth rates at $28{ }^{\circ} \mathrm{C}$.
Various organic acids, alcohols, amino acids and aromatic compounds and hydrogen were tested as electron donors for sulfate reduction. Organic substrates were added from sterile stock solutions at final concentrations between 2 and $10 \mathrm{mM}$. Lactate and acetate were quantified with an HPLC system equipped with an Aminex HPX-87H ionexclusion column (Bio-Rad) and analysed at $60{ }^{\circ} \mathrm{C}$, with $5 \mathrm{mM} \mathrm{H}_{2} \mathrm{SO}_{4}$ as the mobile phase and UV detection at $210 \mathrm{~nm}$ (UVIS 204; Linear Instruments Corp.). Strain JS_SRB250Lac ${ }^{\mathrm{T}}$ utilized a variety of organic substrates including fatty acids and alcohols (Table 1; detailed information is given in the species description). Besides sharing a broad range of substrates with Desulfopila aestuarii MSL86 $^{\mathrm{T}}$, strain JS_SRB250Lac ${ }^{\mathrm{T}}$ also utilized hydrogen, butyrate and succinate as electron donors. Lactate was oxidized incompletely to acetate. This was a common feature of strain JS_SRB250Lac ${ }^{\mathrm{T}}$ and its closest relatives, Desulfopila aestuarii and 'Desulfobacterium corrodens', but the calculation of growth rates at optimum temperatures and $\mathrm{NaCl}$ concentrations for each strain highlighted that Desulfopila aestuarii MSL86 ${ }^{\mathrm{T}}$ grew ten times faster (Suzuki et al., 2007) than strain JS_SRB250Lac ${ }^{\mathrm{T}}$ (maximum growth rate $0.198 \mathrm{day}^{-1}$ ) and 'Desulfobacterium corrodens' IS4, with a doubling time of 3-4 days (Dinh et al., 2004).

Lithoautotrophic growth was tested by repeated transfers into a medium that was free of organic electron donors and overlaid with a headspace of $\mathrm{H}_{2} / \mathrm{CO}_{2}(90: 10, \mathrm{v} / \mathrm{v})$. Measurement of enzyme activities (CO dehydrogenase, 2oxoglutarate: electron acceptor oxidoreductase) was done

Table 1. Selected characteristics for differentiation of strain JS_SRB250Lac ${ }^{\top}$ from related strains

Strains: 1, JS_SRB250Lac ${ }^{\mathrm{T}}$; 2, 'Desulfobacterium corrodens' IS4 (data from Dinh, 2003; Dinh et al., 2004); 3, Desulfopila aestuarii MSL86 ${ }^{\mathrm{T}}$ (Suzuki et al., 2007). All strains formed rod-shaped cells and were positive for utilization of lactate and pyruvate as electron donors for sulfate reduction and fermentation of pyruvate in the absence of sulfate. All strains were negative for utilization of propionate, malate and alanine as electron donors for sulfate reduction and fermentation of lactate and malate.

\begin{tabular}{|c|c|c|c|}
\hline Characteristic & 1 & 2 & 3 \\
\hline DNA G $+C$ content $(\mathrm{mol} \%)$ & 50.3 & 51.9 & 54.5 \\
\hline Optimum salinity $(\% \mathrm{NaCl}, \mathrm{w} / \mathrm{v})$ & $2-3$ & $1-1.5$ & 1 \\
\hline Optimum temperature $\left({ }^{\circ} \mathrm{C}\right)$ & 28 & $28-30$ & 35 \\
\hline \multicolumn{4}{|l|}{$\begin{array}{l}\text { Utilization of electron donors (final } \\
\text { concentration, } \mathrm{mM} \text { ) }\end{array}$} \\
\hline $\mathrm{H}_{2}$ & + & + & - \\
\hline $\mathrm{H}_{2}$ plus acetate $(2)$ & + & + & - \\
\hline n-Butyrate (5) & + & - & - \\
\hline Fumarate (10) & + & - & + \\
\hline Succinate (10) & + & - & - \\
\hline \multicolumn{4}{|c|}{$\begin{array}{l}\text { Utilization of electron acceptors (final } \\
\text { concentration, } \mathrm{mM} \text { ) }\end{array}$} \\
\hline Thiosulfate (10) & - & - & + \\
\hline
\end{tabular}


as described previously (Galushko \& Schink, 2000; Kuever et al., 2001). Strain JS_SRB250Lac ${ }^{\mathrm{T}}$ utilized hydrogen as an electron donor and carbon dioxide/bicarbonate as sole carbon sources. In a cell-free extract of strain JS_SRB250Lac ${ }^{\mathrm{T}}$, active CO dehydrogenase was found [205 nmol (mg protein $\left.{ }^{-1}\right) \min ^{-1}$ ], whereas 2-oxoglutarate: electron acceptor oxidoreductase (a key enzyme in the citric acid cycle) was not detected. This indicated the operation of the reductive acetyl-CoA pathway (WoodLjungdahl pathway) for $\mathrm{CO}_{2}$ fixation (Thauer, 1988). Growth in sulfate-free medium with lactate $(20 \mathrm{mM})$ as electron donor was observed with sulfite $(2 \mathrm{mM})$ as an electron acceptor, but not with nitrate $(5 \mathrm{mM})$ or thiosulfate $(10 \mathrm{mM})$. Fermentative growth occurred with pyruvate and fumarate, but not with lactate or malate (10 mM each).

'Desulfobacterium corrodens' IS4 and JS_SRB250Lac ${ }^{\mathrm{T}}$ were phylogenetically more closely related than were Desulfopila aestuarii MSL86 ${ }^{\mathrm{T}}$ and JS_SRB250Lac ${ }^{\mathrm{T}}$, but they clearly differed with respect to their physiological properties. The strains originated from either surface or subsurface sediments and the lower salinity optimum of 'Desulfobacterium corrodens' IS4 (1.0-1.5\%o) might be inferred from its exposure to fresh water in surface sediments. Beside its striking ability to oxidize elemental iron anaerobically, 'Desulfobacterium corrodens' IS4 was shown to utilize only a few other electron donors, e.g. lactate and pyruvate. Cultivation with these alternative electron donors yielded only poor growth compared with the utilization of elemental iron (Dinh et al., 2004). In contrast, strain JS_SRB250Lac ${ }^{T}$ was nutritionally versatile, utilizing a variety of short-chain organic acids and alcohols as well as hydrogen as electron donors, but did not utilize elemental iron as an electron donor (Dennis Enning, personal communication).

For cellular fatty acid analysis, cells of strain JS_SRB250 $\mathrm{Lac}^{\mathrm{T}}$ and 'Desulfobacterium corrodens' IS4 were grown with lactate $(20 \mathrm{mM})$ and sulfate $(28 \mathrm{mM})$ and harvested from the late exponential phase by centrifugation. Fatty acid methyl esters were obtained by saponification, methylation and extraction (Sasser, 1997). Positions of double bonds in fatty acid methyl esters were determined by analysis of their dimethyl disulfide (DMDS) adducts according to the method of Dunkelblum et al. (1985). Fatty acid methyl esters were quantified via GC-FID (Hewlett Packard HP 5890 Series II gas chromatograph). The major cellular fatty acids of strain JS_SRB250 $\mathrm{Lac}^{\mathrm{T}}$ were $\mathrm{C}_{16: 0}, \mathrm{C}_{18: 0}, \mathrm{C}_{16: 1} \omega 7$, $\mathrm{C}_{16: 1} \omega 5$ and $\mathrm{C}_{17: 0}$ cyclo. Significant differences in the cellular fatty acid profiles of strains JS_SRB250 $\mathrm{Lac}^{\mathrm{T}}$ and 'Desulfobacterium corrodens' IS4 compared with the profile of Desulfopila aestuarii MSL86 ${ }^{\mathrm{T}}$ were the presence and large relative amounts of the cyclopropane fatty acid $\mathrm{C}_{17: 0}$ cyclo (15.3 and $22.5 \%$, respectively) and the absence of hydroxy and unsaturated branched-chain fatty acids in the former strains (Table 2).

The $\mathrm{G}+\mathrm{C}$ content of the genomic DNA was determined by means of HPLC at the Identification Service of the DSMZ
Table 2. Cellular fatty acid compositions of strain JS_SRB250Lac ${ }^{\top}$ and related strains

Strains: 1, JS_SRB250Lac ${ }^{\mathrm{T}}$; 2, 'Desulfobacterium corrodens' IS4 (data from this study); 3, Desulfopila aestuarii $\operatorname{MSL86}^{\mathrm{T}}$ (data from Suzuki et al., 2007). Values are percentages by weight of total fatty acids; - , not detected/not reported.

\begin{tabular}{|lrrc|}
\hline Fatty acid & $\mathbf{1}$ & $\mathbf{2}$ & $\mathbf{3}$ \\
\hline Saturated straight-chain & & & \\
$\mathrm{C}_{14: 0}$ & 1.1 & 1.2 & 1.4 \\
$\mathrm{C}_{15: 0}$ & 1.6 & 1.3 & - \\
$\mathrm{C}_{16: 0}$ & 23.3 & 15.6 & 33.6 \\
$\mathrm{C}_{17: 0}$ & 8.3 & 5.9 & 3.4 \\
$\mathrm{C}_{18: 0}$ & 11.5 & 3.9 & 2.5 \\
Unsaturated straight-chain & & & \\
$\mathrm{C}_{15: 1} \omega 6$ & - & 1.2 & 1.1 \\
$\mathrm{C}_{16: 1} \omega 9$ & 0.7 & - & - \\
$\mathrm{C}_{16: 1} \omega 7$ & 18.3 & 11.1 & 6.0 \\
$\mathrm{C}_{16: 1} \omega 5$ & 11.4 & 21.9 & 17.1 \\
$\mathrm{C}_{17: 1} \omega 6$ & - & 1.6 & 13.7 \\
$\mathrm{C}_{18: 1} \omega 7$ & 8.6 & 7.6 & 1.7 \\
$\mathrm{C}_{18: 1} \omega 5$ & - & 3.9 & 2.7 \\
Cyclic fatty acids & & & \\
$\mathrm{C}_{17: 0}$ cyclo & 15.3 & 22.5 & - \\
Hydroxy fatty acids & - & - & 4.5 \\
Unsaturated branched-chain fatty acids & - & - & 4.6 \\
& & & \\
\hline
\end{tabular}

(Braunschweig, Germany). Nucleic acid extraction, amplification, cloning and sequencing of the $16 \mathrm{~S}$ rRNA gene of JS_SRB250Lac ${ }^{\mathrm{T}}$ were performed as described previously (Gittel et al., 2008). Phylogenetic trees based on 16S rRNA gene sequence datasets ( $>1400 \mathrm{nt}$ ) were constructed using the neighbour-joining and maximum-likelihood algorithms implemented in the ARB program package (Ludwig et al., 2004). In addition, a fragment containing approx. $1.9 \mathrm{~kb}$ of the $d s r A B$ gene (encoding the $\alpha$ - and $\beta$-subunits of the dissimilatory sulfite reductase) was amplified, cloned and sequenced according to Kjeldsen et al. (2007). A custom-designed internal primer (5'-GTGCCTTTGATCTGCAG- $3^{\prime}$ ) was used to complete the sequence. aprBA genes (encoding the adenosine- $5^{\prime}$-phosphosulfate reductase $\alpha$ - and $\beta$-subunits) of strain JS_SRB250Lac ${ }^{\mathrm{T}}$ and Desulfopila aestuarii MSL86 ${ }^{\mathrm{T}}$ were determined using two sets of degenerate primers (AprB-1-FW/AprA-5-RV and AprA-1-FW/Apr-10-RV) as described previously (Meyer \& Kuever, 2007). DsrAB and AprBA amino acid sequencebased phylogenetic trees were inferred using the PhyML program (maximum-likelihood method; http://www. atgc-montpellier.fr/phyml/). Datasets (deduced from $d s r A B$ and aprBA gene sequences) including all available unambiguously aligned DsrAB and AprBA amino acid sequence positions of members of the family Desulfobulbaceae were analysed. Maximum-likelihood trees were constructed using the WAG amino acid substitution model matrices. The robustness of inferred trees was tested by bootstrap analysis with 1000 (16S rRNA gene) and 100 (DsrAB, AprBA) resamplings. 
Phylogenetic analyses of $16 \mathrm{~S}$ rRNA gene sequence datasets showed that strain JS_SRB250 $\mathrm{Lac}^{\mathrm{T}}$ is grouped within the deltaproteobacterial family Desulfobulbaceae (Fig. 1). 'Desulfobacterium corrodens' IS4, isolated from marine sediment, was identified as the closest cultured relative of strain JS_SRB250Lac ${ }^{\mathrm{T}}$, sharing $96.6 \% 16 \mathrm{~S}$ rRNA gene sequence similarity (Dinh et al., 2004), but this name has not been validly published. The closest relative of strain JS_SRB250Lac ${ }^{T}$ with a validly published name was Desulfopila aestuarii MSL86 ${ }^{\mathrm{T}}$ (94.2\% similarity), which was isolated from an estuarine sediment in Japan (Suzuki et al., 2007). The affiliation of strain JS_SRB250Lac ${ }^{T}$ to the Desulfobulbaceae was confirmed by DsrAB and AprBA amino acid sequence analyses (Supplementary Fig. S2). AprBA amino acid sequence analyses additionally supported its close relationship to 'Desulfobacterium corrodens' DSM 15630 (=IS4) (94\% identity) and Desulfopila aestuarii MSL86 $^{\mathrm{T}}$ (90\% identity). dsrAB gene sequences for Desulfopila aestuarii MSL86 ${ }^{\mathrm{T}}$ (Katsuji Ueki, personal communication) and 'Desulfobacterium corrodens' IS4 (this study) could not be determined with the standard procedure and primer variations as described by Loy et al. (2002).

Based on the phylogenetic, physiological and chemotaxonomic characteristics described above, strain JS_SRB250Lac ${ }^{T}$ should be classified as a member of the genus Desulfopila and we propose that it represents a novel species, Desulfopila inferna sp. nov.

\section{Description of Desulfopila inferna sp. nov.}

Desulfopila inferna (in.fer'na. L. fem. adj. inferna that which is, or comes from, below, referring to the isolation of the type strain from a subsurface sediment).
Cells are straight rods with rounded ends, $0.3-0.5 \mu \mathrm{m}$ wide and 1.0-2.0 $\mu \mathrm{m}$ long. Non-motile. The $\mathrm{NaCl}$ range for growth is $0.5-5 \%(\mathrm{w} / \mathrm{v})$ with an optimum between 2 and $3 \%(\mathrm{w} / \mathrm{v})$. The temperature range for growth is $10-35^{\circ} \mathrm{C}$ with an optimum at $28{ }^{\circ} \mathrm{C}$. Utilizes formate, n-butyrate, lactate, fumarate, pyruvate, succinate, valerate, caproate, caprate, ethanol, 1-propanol, 1-butanol, glycerol and proline as electron donors for sulfate reduction. Chemolithoautotrophic growth with $\mathrm{H}_{2}$ plus $\mathrm{CO}_{2}$ /bicarbonate. Does not utilize acetate, propionate, malate, glycine, alanine, serine, betaine, choline, benzoate, sorbitol or mannitol. Sulfate and sulfite serve as electron acceptors. Thiosulfate and nitrate are not utilized. Pyruvate and fumarate are fermented in the absence of electron acceptors. Malate and lactate are not fermented. The genomic DNA G+C content of the type strain is $50.3 \mathrm{~mol} \%$. The major cellular fatty acids are $\mathrm{C}_{16: 0}$, $\mathrm{C}_{18: 0}, \mathrm{C}_{16: 1} \omega 7, \mathrm{C}_{16: 1} \omega 5$ and $\mathrm{C}_{17: 0}$ cyclo.

The type strain is JS_SRB250Lac ${ }^{\mathrm{T}}\left(=\mathrm{DSM} 19738^{\mathrm{T}}=\right.$ NBRC $103921^{\mathrm{T}}$ ), isolated from subsurface sediment from a tidal sand-flat of the German Wadden Sea.

\section{Acknowledgements}

The authors are grateful to Michael Pilzen and Katharina Deutz for their help in analytical procedures. We thank Jürgen Rullkötter for providing facilities to analyse fatty acid methyl esters. Dennis Enning (Max Planck Institute for Marine Microbiology, Bremen, Germany) is acknowledged for testing JS_SRB250Lac ${ }^{\mathrm{T}}$ for its capacity for anaerobic iron oxidation. We thank Ramona Appel (Max Planck Institute for Marine Microbiology, Bremen, Germany) for HPLC analysis of fatty acids. Special thanks go to Nina Schomacker and Markko Remesch for their help in obtaining the APS reductase gene sequences. This work was supported financially by a grant from the

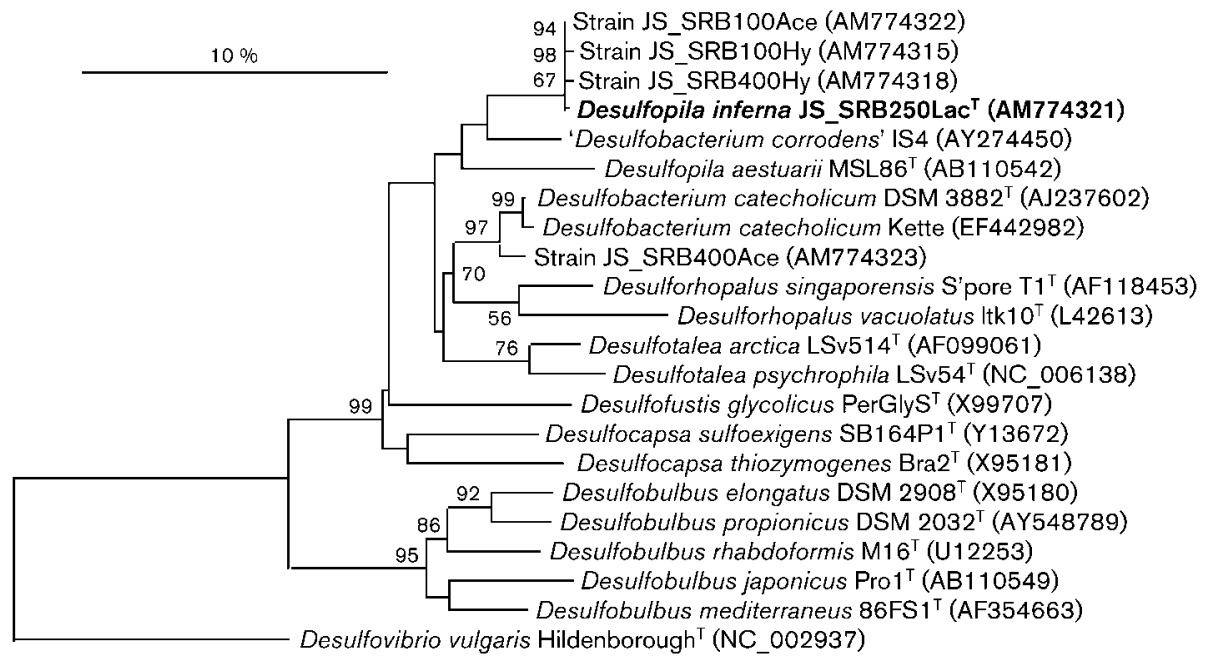

Fig. 1. Neighbour-joining tree showing the affiliation of the $16 \mathrm{~S}$ rRNA gene sequence of strain JS_SRB250Lac ${ }^{\top}$ to selected reference sequences from members of the Deltaproteobacteria. Bootstrap values are percentages based on analysis of 1000 replicates; only values $>50 \%$ are indicated near nodes. The tree topology inferred from maximum-likelihood analysis was similar to that obtained from the neighbour-joining method (not shown). Bar, $10 \%$ sequence divergence. 
Deutsche Forschungsgemeinschaft (FOR432, 'Biogeochemistry of tidal flats').

\section{References}

Beck, M., Dellwig, O., Kolditz, K., Freund, H., Liebezeit, G., Schnetger, B. \& Brumsack, H.-J. (2007). In situ pore water sampling in deep intertidal flat sediments. Limnol Oceanogr Methods 5, 136144.

Billerbeck, M., Werner, U., Bosselmann, K., Walpersdorf, E. \& Huettel, M. (2006a). Nutrient release from an exposed intertidal sand flat. Mar Ecol Prog Ser 316, 35-51.

Billerbeck, M., Werner, U., Polerecky, L., Walpersdorf, E., de Beer, D. \& Huettel, M. (2006b). Surficial and deep pore water circulation governs spatial and temporal scales of nutrient recycling in intertidal sand flat sediment. Mar Ecol Prog Ser 326, 61-76.

Bradford, M. M. (1976). A rapid and sensitive method for the quantitation of microgram quantities of protein utilizing the principle of protein dye-binding. Anal Biochem 72, 248-254.

Cord-Ruwisch, R. (1985). A quick method for the determination of dissolved and precipitated sulfides in cultures of sulfate-reducing bacteria. J Microbiol Methods 4, 33-36.

D'Andrea, A. F., Aller, R. C. \& Lopez, G. R. (2002). Organic matter flux and reactivity on a South Carolina sandflat: the impacts of porewater advection and macrobiological structures. Limnol Oceanogr 47, 10561070.

de Beer, D., Wenzhöfer, F., Ferdelman, T. G., Boehme, S. E., Huettel, M., van Beusekom, J. E. E., Böttcher, M. E., Musat, N. \& Dubilier, N. (2005). Transport and mineralization rates in North Sea sandy intertidal sediments, Sylt-Rømø Basin, Waddensea. Limnol Oceanogr 50, 113127.

Dinh, H. T. (2003) Microbiological study of the anaerobic corrosion of iron. PhD thesis, University of Bremen, Bremen, Germany.

Dinh, H. T., Kuever, J., Mußmann, M., Hassel, A. W., Stratmann, M. \& Widdel, F. (2004). Iron corrosion by novel anaerobic microorganisms. Nature 427, 829-832.

Dunkelblum, E., Tan, S. H. \& Silk, P. J. (1985). Double-bond location in mono-unsaturated fatty acids by dimethyl disulfide derivatization and mass spectrometry: application to analysis of fatty acids in pheromone glands of four Lepidoptera. J Chem Ecol 11, 265-277.

Galushko, A. S. \& Schink, B. (2000). Oxidation of acetate through reactions of the citric acid cycle by Geobacter sulfurreducens in pure culture and in syntrophic coculture. Arch Microbiol 174, 314321.

Gittel, A., Mußmann, M., Sass, H., Cypionka, H. \& Könneke, M. (2008). Identity and abundance of active sulfate-reducing bacteria in deep tidal flat sediments determined by directed cultivation and CARD-FISH analysis. Environ Microbiol 10, 2645-2658.
Huettel, M. \& Rusch, A. (2000). Transport and degradation of phytoplankton in permeable sediment. Limnol Oceanogr 45, 534-549.

Ishii, K., Mußmann, M., MacGregor, B. J. \& Amann, R. (2004). An improved fluorescence in situ hybridization protocol for the identification of bacteria and archaea in marine sediments. FEMS Microbiol Ecol 50, 203-212.

Kjeldsen, K. U., Kjellerup, B. V., Egli, K., Frølund, B., Nielsen, P. H. \& Ingvorsen, K. (2007). Phylogenetic and functional diversity of bacteria in biofilms from metal surfaces of an alkaline district heating system. FEMS Microbiol Ecol 61, 384-397.

Kuever, J., Könneke, M., Galushko, A. \& Drzyzga, O. (2001). Reclassification of Desulfobacterium phenolicum as Desulfobacula phenolica comb. nov and description of strain $\mathrm{Sax}^{\mathrm{T}}$ as Desulfotignum balticum gen. nov., sp. nov. Int J Syst Evol Microbiol 51, 171-177.

Loy, A., Lehner, A., Lee, N., Adamczyk, J., Meier, H., Ernst, J., Schleifer, K. H. \& Wagner, M. (2002). Oligonucleotide microarray for $16 \mathrm{~S}$ rRNA gene-based detection of all recognized lineages of sulfatereducing prokaryotes in the environment. Appl Environ Microbiol 68, 5064-5081.

Ludwig, W., Strunk, O., Westram, R., Richter, L., Meier, H., Yadhukumar, Buchner, A., Lai, T., Steppi, S. \& other authors (2004). ARB: a software environment for sequence data. Nucleic Acids Res 32, 1363-1371.

Meyer, B. \& Kuever, J. (2007). Phylogeny of the alpha and beta subunits of the dissimilatory adenosine- $5^{\prime}$-phosphosulfate (APS) reductase from sulfate-reducing prokaryotes - origin and evolution of the dissimilatory sulfate-reduction pathway. Microbiology 153, 20262044.

Murray, R. G. E., Doetsch, R. N. \& Robinow, F. (1994). Determinative and cytological light microscopy. In Methods for General and Molecular Bacteriology, pp. 21-41. Edited by P. Gerhardt, R. G. E. Murray, W. A. Wood \& N. R. Krieg. Washington, DC: American Society for Microbiology.

Musat, N., Werner, U., Knittel, K., Kolb, S., Dodenhof, T., van Beusekom, J. E. E., de Beer, D., Dubilier, N. \& Amann, R. (2006). Microbial community structure of sandy intertidal sediments in the North Sea, Sylt-Rømø Basin, Wadden Sea. Syst Appl Microbiol 29, 333-348.

Røy, H., Lee, J. S., Jansen, S. \& de Beer, D. (2008). Tide-driven deep pore-water flow in intertidal sand flats. Limnol Oceanogr 53, 15211530.

Sasser, M. (1997). Identification of bacteria by gas chromatography of cellular fatty acids, MIDI Technical Note 101. Newark, DE: MIDI Inc.

Suzuki, D., Ueki, A., Amaishi, A. \& Ueki, K. (2007). Desulfopila aestuarii gen. nov., sp. nov., a Gram-negative, rod-like, sulfatereducing bacterium isolated from an estuarine sediment in Japan. Int J Syst Evol Microbiol 57, 520-526.

Thauer, R. K. (1988). Citric-acid cycle, 50 years on: modifications and an alternative pathway in anaerobic bacteria. Eur J Biochem 176, 497508. 